\title{
Coating effect of micro-sized droplets impacting on low temperature spherical particles
}

\section{Wu, X. ${ }^{\text {a }}$ Ma, X. ${ }^{\text {b }}$ Xu, Q. ${ }^{\text {a }}$ Li, Z..$^{\mathrm{a}^{*}}$; Wang, R. ${ }^{\mathrm{a}}$}

anternational Joint Research Center of Low-Carbon Green Process Equipment; College of Mechanical Engineering, Tianjin University of Science \& Technology, Tianjin 300222, China.

${ }^{b}$ Tianjin Key Laboratory of Integrated Design and On-line Monitoring for Light Industry \& Food Machinery and Equipment, Tianjin 300222, China.

*E-mail of the corresponding author:zyli@tust.edu.cn (Z. Li).

\begin{abstract}
In this paper, the effect of spray droplets on the coating of cold spherical particles was studied.The microcapsule granulator produces micron-sized droplets to coat the spherical particles in cold storage, and the high-definition camera and precision balance are used to photograph and weigh the particles before and after the spraying. The droplets are obtained by using the image and data processing technology coating area and coating quality, the droplet coating effect was evaluated by a number of dimensionless parameters such as coating ratio and mass ratio.By orthogonal design experiment and uncertainty analysis, the effects of droplet size and flow rate, spherical particle temperature and diameter on coating effect were studied, and the effect of droplet group coating on low temperature spherical particles was obtained.
\end{abstract}

Keywords: Spray freeze drying; Droplets; coating; Spherical particles. 


\section{Introduction}

Since 1948, when Benson et al. first used the technique of spray freezing to study the surface area of protein particles ${ }^{[1]}$, this technology has been developing for more than 60 years and has obtained some representative research results. For example, in 1964 Werly used spray-frozen technology to obtain submicron powder products, marking that the spray freezing technology has been developed to the stage of producing products ${ }^{[3]}$; in 1989 , Chen Zuyao and others first prepared Ba-Y by means of SFD method. Cu-O system composite oxide ultrafine powder ${ }^{[2]}$; 1994, the technology applied for a European patent; in 1998, Maa et al. proposed the preparation of protein microspheres using SFD technology for the first time ${ }^{[5]}$; in 2006, it achieved regular freezing. Dry alternative to vacuum freeze-drying reduces the energy consumption of SFD technology ${ }^{[6]}$. After more than half a century of development, SFD technology is gradually maturing, and it has been applied in the fields of medicine, food, chemical products, and biological products ${ }^{[7]}$.

In order to solve the phenomena of agglomeration of powders, non-uniform powder particle size and other phenomena, to further improve the application of spray freeze-drying technology in engineering practice and achieve mass production, Li Zhanyong et al ${ }^{[4]}$ proposed an inert particle fluidized bed spray freeze-drying Equipment. In order to deeply study the freezing mechanism of atomized droplets impacting the carrier particles, this paper studied the coating area of cryogenic spherical particles by droplets in experiments.

\section{Materials and Methods}

\subsection{Experimental Materials}

Since the coated particles were image-collected after the coating experiment, in order to facilitate the image processing, the material used in this experiment was ink. The inert carrier particles use different diameters of organic glass spheres. The effects of different experimental conditions on the droplet coating process were experimentally studied. By setting different flow rates of 6 and $8 \mathrm{~mL} / \mathrm{min}$, atomized droplets of diameter $0.2 \mathrm{~mm}$ were obtained. The diameters of the glass spheres were taken as 3, 4 and $5 \mathrm{~mm}$, respectively. Each set of experiments was performed 3 times.

\subsection{Experimental device}

The droplets are generated by a Droplets generator, which uses laminar liquid jets and vibrates at high frequencies to produce extremely uniform round microcapsule particles as shown in Figure.1. Applied to the protection and storage of drugs, microorganisms, 
enzymes or cells, the purpose of microencapsulation is to use a polymer mechanism to protect or stabilize the active ingredient, and it can also be used to produce uniform atomized droplets. The device can generate highly reproducible uniform drop particles whose particle size can be pre-set to $0.2 \mathrm{~mm}$ depending on the choice of nozzle, with a narrow particle size distribution ( $<5 \%$ standard deviation).

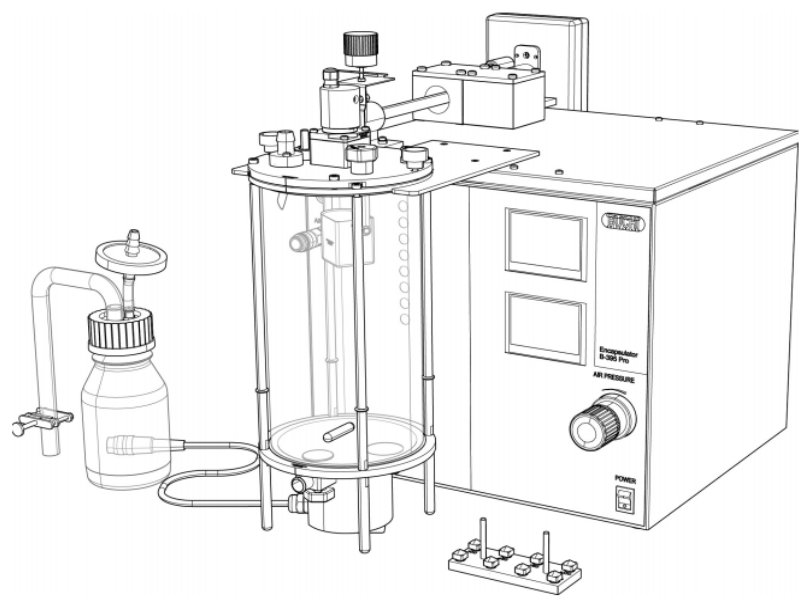

Fig.1 Droplets generator

For this study, the collision process of atomized droplets impinging on a solid surface at a temperature of $-25^{\circ} \mathrm{C}$ was studied. Such a low degree of subcooling metal particles at room temperature, the water vapor in the air quickly frozen on the metal surface to form ice, change the structure of the particle surface structure impact on the droplet collision process. In this experiment, a freezer (Haier Company) was used as a cooling space. Its cooling range was as low as $-50{ }^{\circ} \mathrm{C}$. The internal dimensions of the refrigerator were $100 \mathrm{~cm}$ in length, $70 \mathrm{~cm}$ in width, and $60 \mathrm{~cm}$ in height. The top has a $12 \mathrm{~cm}$ diameter feed hole.

\subsection{Experimental parameters}

The experimental data image was processed by Image J software, and the projected area of the coating liquid film was calculated by converting the image into a grayscale image and pixel scanning to obtain the ink coating area. As shown in Figure. 2. 


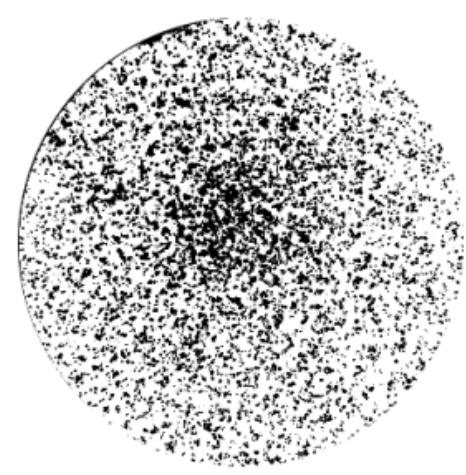

(a)Total area of coated projection $S_{1}$

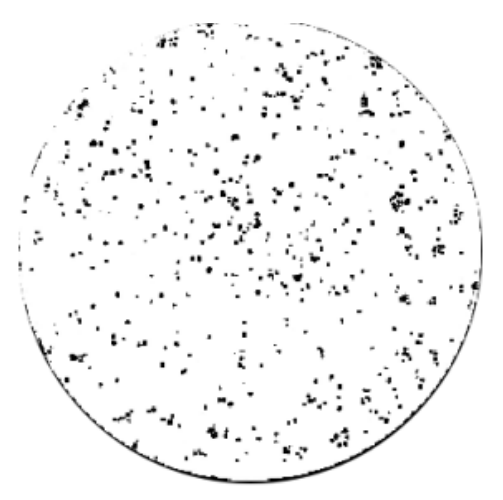

(b) After coating area removed $S_{2}$

Fig.2 Coated image after processing

Coating area:

$$
S=S_{1}-S_{2}
$$

The $S_{1}$ refers to the total area of the projection of the projection, and the $S_{2}$ refers to the projection area after the removal of the particles.

Coating ratio:

$$
c=\frac{S}{n \times \pi r^{2}} \times 100 \%
$$

The $\mathrm{n}$ refers to the number of particles, and $\mathrm{R}$ refers to the radius of the particles.

Coating amount:

$$
M=\left(M_{1}-M_{2}\right)-\left(m_{1}-m_{2}\right)
$$

In the formula, $M_{1}$ refers to the total mass after coating, $M_{2}$ refers to the total mass before coating, $m_{1}$ refers to the mass of the empty disk after coating, and $m_{2}$ refers to the mass of the empty disk before coating.

\section{Results and Discussion}

\subsection{Effect of Particle Diameter Change on Coating}

The background of the experimental study in this paper is the collision and coating of atomized droplets with fluidized, undercooled carrier particles. For this reason, it is of great significance to investigate the influence of particle diameter on the coating area of droplets. 
In this experiment, $0.5,1,2$, and $3 \mathrm{~g}$ of ink were coated on glass balls with diameters of 3, 4, and $5 \mathrm{~mm}$ at a flow rate of $6 \mathrm{~mL} / \mathrm{min}$ and $8 \mathrm{~mL} / \mathrm{min}$, respectively, of droplets with an average diameter of $0.2 \mathrm{~mm}$. Study the change in coated area with ball diameter.
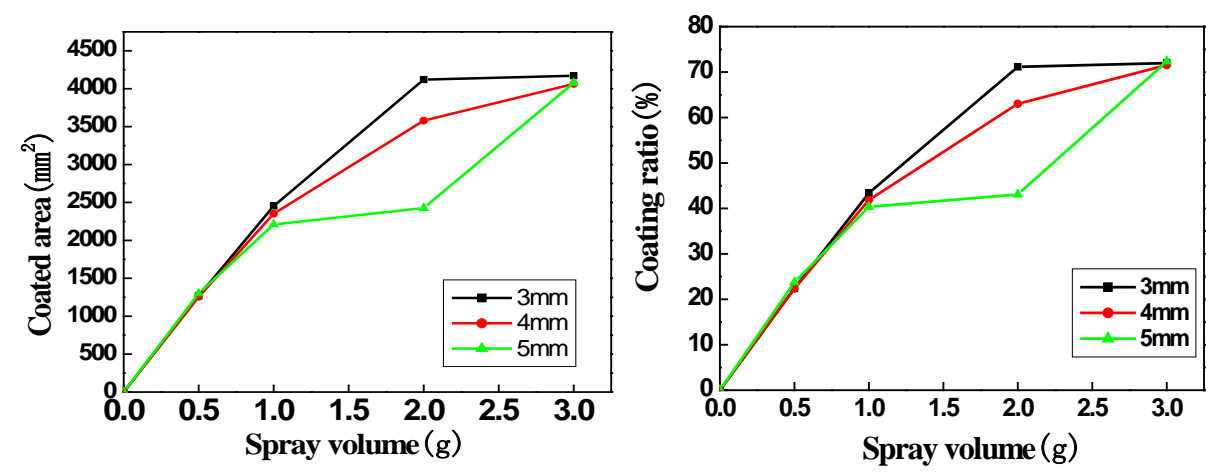

(a) flow rate of $6 \mathrm{~mL} / \mathrm{min}$
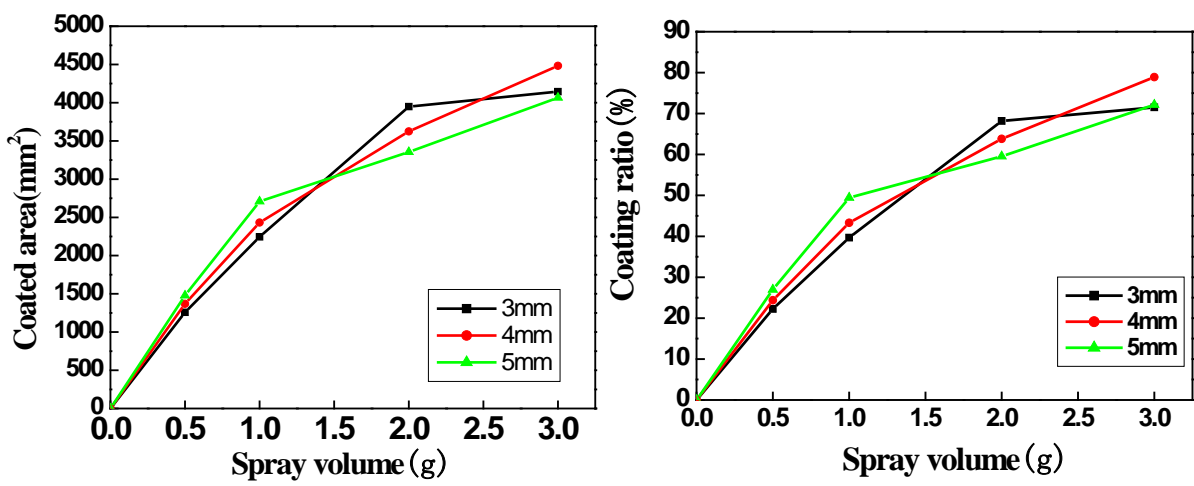

(b) flow rate of $8 \mathrm{~mL} / \mathrm{min}$

Fig. 3 Variation of coating area and coating ratio with spray amount for different particle sizes under two flow rates

As shown in Fig. 3(a), at a spray flow rate of $6 \mathrm{~mL} / \mathrm{min}$, from the start of spraying to when the spray amount reaches $1 \mathrm{~g}$, the coating rate hardly varies with the diameter of the particles, the coated area of the particles is basically the same, and the coating ratio is about $40 \%$, when the spray amount is $1-2 \mathrm{~g}$, the particle diameter increases, the coating rate decreases, from 2-3 g, the particle diameter increases, the coating rate increases, but when the spray amount is $3 \mathrm{~g}$, three kinds The coated area of the particles is substantially the same, and the coating ratio reaches $70 \%$. As shown in Fig. 3(b), at a flow rate of $8 \mathrm{~mL} / \mathrm{min}$, from the start of spraying to when the spray amount reaches $1 \mathrm{~g}$, the particle diameter increases, the coating rate gradually increases, and the particle diameter increases from 1-3 g. Increasing, the coating rate decreases. However, when the spray amount was $1.5 \mathrm{~g}$, the 
coating area of the three particle sizes was substantially the same, and the coating ratio was about $55 \%$.

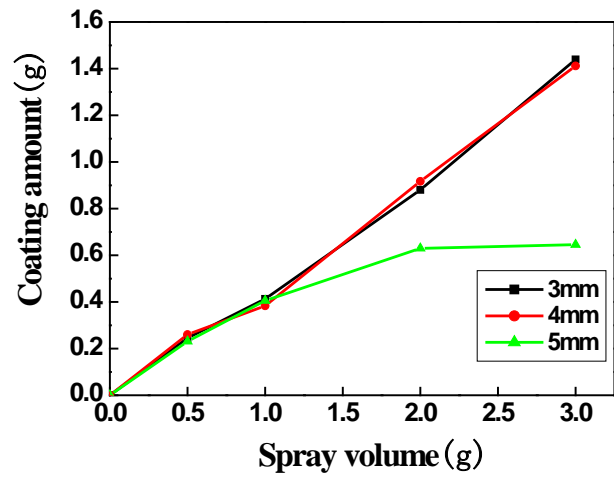

(a) flow rate of $6 \mathrm{~mL} / \mathrm{min}$

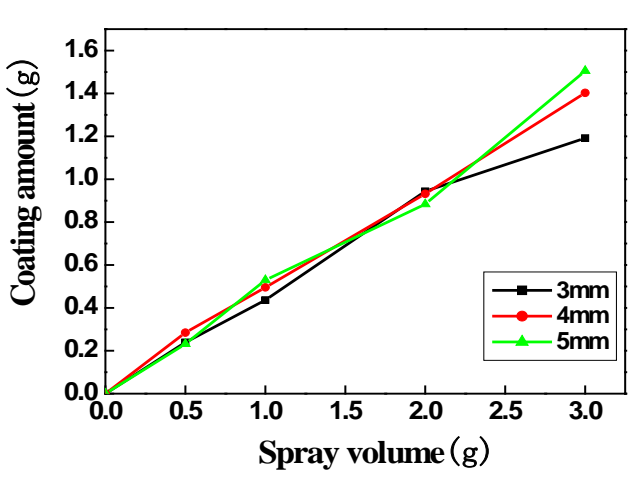

(b)flow rate of $8 \mathrm{~mL} / \mathrm{min}$

Fig. 4 Change of coating amount with spray amount under different flow rate and different particle size

As shown in Fig. 4(a), at a spray flow rate of $6 \mathrm{~mL} / \mathrm{min}$, the coating amount increases as the amount of spray increases, coating of 3, $4 \mathrm{~mm}$ particles is almost the same, but the coating amount of $5 \mathrm{~mm}$ particles is apparently seen. It is much smaller than other diameter particles. As shown in Fig. 4(b), at the spray flow rate of $8 \mathrm{~mL} / \mathrm{min}$, the spraying amount of the three kinds of particle granules was basically the same from the beginning of the spraying to $2 \mathrm{~g}$, and after $2 \mathrm{~g}$, the particle diameter increased, and the coating was applied. The amount increases.

\subsection{Influence of Change in Atomization Flow Rate on Coating}

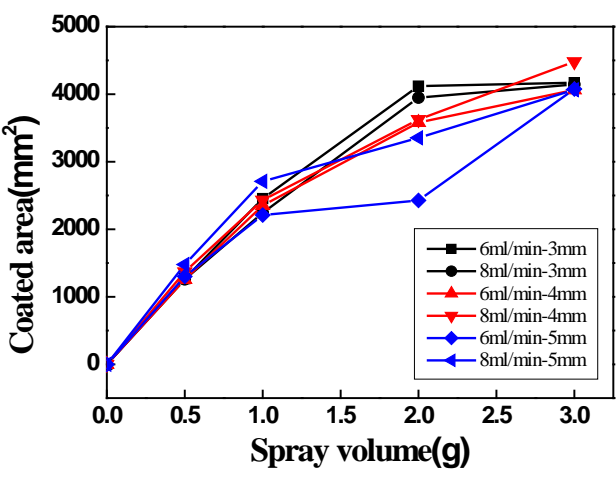

(a)

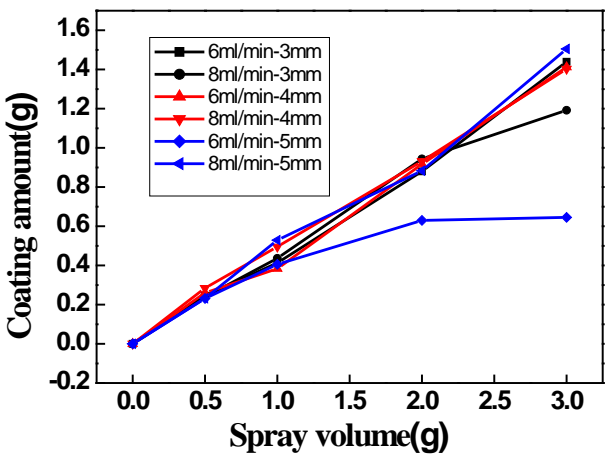

(b)

Fig. 5 Change in Coating Area with Spray Volume 
As shown in Fig. 5(a), when the particle diameter is $3 \mathrm{~mm}$, the coated area under the two flow rates shows almost the same change trend; when the particle diameter is $4 \mathrm{~mm}$, the coated area at $8 \mathrm{~mL} / \mathrm{min}$ is slightly larger than $6 \mathrm{~mL} / \mathrm{min}$ when the same spray amount is applied; When the particle diameter is $5 \mathrm{~mm}$, the coating area under $8 \mathrm{~mL} / \mathrm{min}$ conditions is much higher than $6 \mathrm{~mL} / \mathrm{min}$ under the same spray amount condition, but when the spray amount reaches $3 \mathrm{~g}$, the coated area is the same. It can be seen that when the particle diameter is small, the flow has little influence on the coating. As the particle diameter increases, the influence of the flow on the coating increases, and the larger the flow, the larger the coated area. As shown in Fig. 5(b), when the particle diameter is 3 or $4 \mathrm{~mm}$, the coating amount is basically the same with the variation of the spray amount at different flow rates; with a particle diameter of $5 \mathrm{~mm}$, the coating flow rate of $6 \mathrm{~mL} / \mathrm{min}$ is much lower than the flow rate of $8 \mathrm{~mL} / \mathrm{min}$.

From the above two figures, it can be seen that the particle diameter has a significant effect on the coating. When the particle diameter increases, the curvature of the particle surface decreases, so that the droplets are likely to accumulate on the surface of the particles, so that the coating area is reduced; when the flow rate increases At that time, the influence of the curvature of the particles on the coating is reduced, because the kinetic energy of the spray droplets increases, so that the droplets spread more, so that the influence of the curvature of the particles is reduced.

\section{Conclusions}

When the spray flow rate is $6 \mathrm{~mL} / \mathrm{min}$, the particle diameter has little effect on the coating when the spraying starts to $1 \mathrm{~g}$. With the progress of the coating, the larger the particle diameter, the smaller the coating rate; when the spray flow rate is $8 \mathrm{~mL} / \mathrm{min}$, the larger the particle diameter before the coating ratio is $55 \%$, the larger the coated area, and the larger the particle diameter and the smaller the coated area after the 55\% coating ratio.

With the same amount of spray, as the particle diameter increases, the flow rate increases and the coating area increases, but when the spray amount reaches $3 \mathrm{~g}$, the coated area is almost the same; when the particle size becomes larger, the spray flow increases. The coating amount increases.

The authors acknowledge Projects supported by the National Natural Science Foundation of China (Grant No. 31571906 \& No.21506163).

\section{References}

[1] Rogers, S.; Wu, W. D.; Saunders, J. Characteristics of milk powders produced by spray freeze drying. Drying Technology 2008, 26 (4), 404-412. 
[2] Leuenberger, H.; Plitzko, M.; Puchkov, M. Spray-freeze-drying in a fluidized bed at normal and low pressure. Drying Technology 2006, 24 (6), 711-719.

[3] Yeom, G. S.; Song, C. S. Experimental and numerical investigation of the characteristics of spray-freeze drying for various parameters: effects of product height, heating plate temperature, and wall temperature. Drying Technology 2010, 28 (2), 165-179.

[4] Zhanyong Li et al. An inert particle spray freeze-drying equipment and method. Chinese patent. 201110103036.9, 2011.

[5] Hans Leuenberger. Process of drying a particulate material and apparatus for implementing the process. US Patent, 4608764, 1986.

[6] Worthington, A. M. T. he splash of a drop and allied phenomena. Smithsonian Report 79, 972-982.

[7] Gangtao Liang, S. S. et al. Experimental observations of special phenomena of liquid droplets striking a slanted surface liquid film. Acta Physica Sinica, 2013, 62 (8), 084707-1-7. 